\title{
Development of a Chinese Version of the Suicide Intent Scale
}

\author{
Susan S.F. Gau, MD, PhD, Chin-Hung Chen, MD, \\ Charles T.C. Lee, PhD, Jung-Chen Chang, PhD, \\ and Andrew T.A. Cheng, MD, PhD, DSc (London), FrCPsych
}

This study established the psychometric properties of the Chinese version of the Suicide Intent Scale (SIS) in a clinic- and community-based sample of 36 patients and 592 respondents, respectively. Results showed that the Chinese SIS demonstrated good inter-rater and test-retest reliability. Factor analysis generated three factors (Precautions, Planning, and Seriousness) explaining 92.9\% of the total variance with high internal consistency. It was moderately correlated with depressive symptoms. Results suggest that the Chinese SIS is a reliable and valid instrument for use in assessing the extent of suicidal intention among subjects with deliberate self-harm in ethnic Chinese populations.

Suicide has become an important global public health issue since the last decade and its impact on the entire society is still increasing (Hawton, 2000). The WHO has predicted that the global incidence of suicide will reach approximately 1.53 million people per year, and 10 to 20 times as many individuals will

Susan S.F. Gau, MD, PhD, is with the Department of Psychiatry, College of Medicine, National Taiwan University and National Taiwan University Hospital; Chin-Hung Chen, MD, is with Tsao-Tun Psychiatric Center, Nantou, Taiwan; Jung-Chen Chang, $\mathrm{PhD}$, is with Ching Kuo Institute of Management and Health, Keelung, Taiwan; and Andrew T.A. Cheng, MD, PhD, DSc, FRCPsych, and Charles T.C. Lee, PhD, are with the Institute of Biomedical Sciences, Academia Sinica (Drs Cheng and Lee), Taipei, Taiwan.

The authors would like to thank all members of the research team and the 12 interviewers who conducted the interviews among 592 community respondents. This study received no funding.

Address correspondence to Professor Andrew Cheng, Institute of Biomedical Sciences, Academia Sinica, Taipei, Taiwan; E-mail: bmandrew @gate.sinica.edu.tw. attempt suicide by the year 2020 (Bertolote $\&$ Fleischman, 2002). The Chinese populations in China (Wang et al., 2003), Hong Kong (Yip, Law, \& Law, 2003), and Taiwan have also experienced a recent increase of suicide.

To identify major predictive factors for suicide is an important component in suicide prevention, and the extent of suicide intent, defined as the seriousness or intensity of one's wish to terminate one's own life (Beck \& Herman, 1974), has been reported to significantly predict subsequent suicides (Hjelmeland et al., 1998; Lönnqvist \& Tolppanen, 1985; Pallis, Gibbons, \& Pierce, 1984; Pierce, 1981; Suokas \& Lonnqvist, 1991). The predictive power of suicide intent on eventual suicide is even stronger than previous attempts or hopelessness (Zhang \& Norvilitis, 2002). It has thus been suggested that measurement of suicide intent should be routinely included in clinical practice in the suicide prevention program (Harriss \& Hawton, 2005; Hjelmeland et al., 2002; Pierce, 1981).

Few studies have comprehensively assessed the severity of suicide intent among high-risk groups. The Suicide Intent Scale 
(SIS) has been one of the most commonly used instruments measuring suicide intent in clinical settings (Beck \& Herman, 1974). The SIS has intentionally excluded items regarding medical lethality or the effectiveness of the suicide act in its construct (Beck, Beck, \& Kovacs, 1975).

Several studies have evaluated the psychometric properties of the SIS (Beck \& Lester, 1976; Beck \& Herman, 1974; Diaz et al., 2003; Kingsbury, 1993; Mieczkowski et al., 1993; Spirito, Sterling, Donaldson, \& Arrigan, 1996; Wetzel, 1976). These studies reported high internal reliability of the SIS with Cronbach's alpha coefficients ranging from 0.86 (Diaz et al., 2003) to 0.95 (Beck \& Herman, 1974), as well as high inter-rater reliability with kappa coefficients ranging from 0.81 (Mieczkowski et al., 1993) to 0.95 (Beck \& Herman, 1974). For construct validity, factor analyses have demonstrated two (Diaz et al., 2003; Mieczkowski et al., 1993), three (Spirito et al., 1996), or four factors (Beck \& Lester, 1976; Kingsbury, 1993; Wetzel, 1976), suggesting that suicidal intent may not only contain a single dimension. Regarding concurrent validity, the SIS is moderately correlated with measures of depression (Chance, Kaslow, \& Baldwin, 1994; Minkoff, Bergman, Beck, \& Beck, 1973; O’Brien, Holton, Hurron, Watt, \& Hassanyeh, 1987; Platt \& Dyer, 1987; Silver, Bohnert, Beck, \& Marcus, 1971), hopelessness (Beck \& Herman, 1974; Platt \& Dyer, 1987), and lethality of suicide attempts (Haw, Hawton, Houston, \& Townsend, 2003). A higher SIS score is noted in suicide attempters with major depression (Astruc et al., 2004). However, findings concerning predictive validity of the SIS is conflicting (Samuelsson, Jokinen, Nordstrom, \& Nordstrom, 2006; Suominen, Isometsa, Ostamo, \& Lonnqvist, 2004) with a low positive predictive power, which might be explained by the low incidence rate of suicide (Harriss \& Hawton, 2005).

Although the SIS has been used in almost all studies investigating suicide intent in western societies (O'Donnell, Farmer, \& Catalan, 1996; Suominen, Isometsa, Heila, Lonnqvist, \& Henriksson, 2002), to the best of our knowledge, there has been no report of using the SIS in other parts of the world, where the characteristics of suicidal act and the expression of suicide intent might be considerably different from that in western societies (Cheng \& Lee, 2000).

Previous studies reported broadly similar risk factors for suicide in Taiwan and in western countries, including depressive disorder, alcoholism, personality disorder characterized by impulsivity, life events, family history of suicide, and previous suicide attempt(s) (Cheng, 1995; Cheng, Mann, \& Chan, 1997; Cheng, Chen, Chen, \& Jenkins, 2000). However, little is known about the level of suicide intent among suicides and its possible contribution to differential suicide rates in Chinese populations around the globe (Phillips et al., 2002). In order to accurately measure suicide intent in Chinese populations, we have developed a Chinese version of the SIS and examined its reliability and validity in two samples of respondents with a history of recent deliberate self harm (DSH) in this study. We have also examined the feasibility for nonphysician mental health staffs to administer the interview items of the Chinese SIS.

\section{METHODS}

\section{Development of the Chinese Version of the SIS}

The SIS consists of 8 items (objective circumstances section) for interview and 7 items for self-report. The former (objective circumstances) inquires about the factual aspects of the attempt and the surrounding events. The latter (self-report section) concerns the subject's thoughts and feelings about the former, which might be more vulnerable to distortion by people with selfharm who might wish to enhance the social desirability of suicidal behavior or exaggerate the wish to die. Each of the SIS items is rated on a 3 -point Likert-type scale (0-2) with a total score of $0-30$.

A research team comprising five senior 
psychiatrists and five other mental health professionals conducted the development of the SIS. A two-stage translation was first carried out by two research psychiatrists fluent in English. The other three psychiatrists then independently examined these two versions. Comparing with the original English version, the back-translated English version did not demonstrate any semantic distortion or any missing of the content. A pretest among 40 psychiatric patients with DSH was then conducted with subsequent modifications for psycholinguistic equivalents. All the 15 items are found to be relevant and understandable by respondents. However, the wordings and examples of actions given in some item questions need to be modified (details of the modification are available from A.T.A.C. upon request). For example, the original question for item 7 (suicide note) was modified to include both suicide note and "last words" (more frequently used by the elderly). The original question for item 5 (final acts in anticipation of death) was modified with common acts observed in Taiwan, including seeing significant family members or favorite possessions, putting personal belongings in a good order, giving instructions for important things, etc.

\section{Study Subjects and Procedures}

The institutional review board of the Tsaotun Psychiatric Center, Nantou, Taiwan approved this study. Informed consent was obtained from each study subject in advance after explanation of the purpose and procedure of this study and reassurance of confidentiality.

The reliability and validity of the Chinese SIS were examined in two samples with a recent history of DSH: one of 36 psychiatric patients and one of 592 representative respondents recruited from the community.

DSH means all acts of deliberate selfpoisoning or self-injury, irrespective of the degree of suicidal intent (NHS Centre for Reviews and Dissemination, 1998). The other terms in general use, namely attempted sui- cide and parasuicide, would be subsumed within this definition.

The 36 patients were aged 18 years and over without any obvious cognitive or psychotic symptoms. Among them, 18 were interviewed using the first 8 items of the objective circumstances section in the Chinese SIS by one of the team members. These interviews were audio taped and subsequently rated by the other 9 raters. Ratings for the first three interviews from all raters were compared and any discrepancies were discussed item by item in a team meeting without changes made to the ratings. The rest of the 18 patients were asked to fill out the 7 self-reported items twice, with the second one done 7 to 14 days $($ Mean $=9.1, S D=2.9)$ after the first reports.

The internal consistency, construct validity and convergent validity were then conducted among the 592 subjects with DSH recruited from a community-based suicide register system in Nantou County, Taiwan, aiming at the identification of all inhabitants who had a DSH. Nantou County encompasses suburban and rural areas with a total population of approximately 500,000. The DSH acts were identified using a whole population approach in two stages. In the first stage, subjects with DSH were reported by informants to the case register system set up by Nantou Health Bureau. Informants included people working in places where cases were seen or assessed, that are (1) health personnel, including emergency room nurses in hospitals, general practitioners as well as local public health nurses; and (2) social service providers such as firefighters, police, social workers, and NGO workers. DSH cases were then approached by the staff of Nantou Community Mental Health Center.

The 592 study subjects who gave their consent to participate in this study occupied $36.4 \%$ of a total of 1,627 cases identified during June, 2001, and October, 2005. Their mean age was 38.66 years $(S D=15.87$, ranging from 12 to 88$)$, with males $(40.69, S D=$ 17.72) older than females $(37.55, S D=14.66)$, $(t=0.021, p=0.021)$. The mean age (37.18, $S D=15.32$ ) of our sample was slightly lower 
than the total cases $(t=2.262, p=0.024]$ and the gender distribution was the same as the total cases (92 female, $64.8 \% ; p=0.97$ ). The distributions of educational levels of 577 participants (15 missing data) were 14 illiterate (2.4\%), 125 primary school (21.7\%), 188 junior high (32.6\%), 299 senior high (39.7\%), and 21 college and higher (3.6\%). All of them were invited to receive a detailed interview assessment within one month of the index event, conducted either in hospital (if admitted) or in their own homes.

The interview assessments covered the Chinese SIS, alcohol problems, life events, family history, and past history of suicide/ $\mathrm{DSH}$, the Chinese version of the Center for Epidemiologic Studies-Depression Scale (CESD). The interviews were conducted by psychiatric nurses, social workers, and clinical psychologists $(N=12)$ who received a training in the use of the instrument. They also carried out an inter-rater reliability of the Chinese SIS (objective circumstance) using the same 18 psychiatric patients.

\section{The Chinese CES-D}

The CES-D, a 20-item self-reported depression symptom scale, was developed by the Center for Epidemiologic Studies in the States (Weissman, Sholomskas, Pottenger, Prusoff, \& Locke, 1977). It was used to screen for current depressive symptoms during the past week. Each item is rated on a 4-point Likert scale from 0 for Rarely (less than one day per week) to 3 for Always (5 days or more per week), generating a total score of the 20 items ranging from 0 to 60 . The scale has been proved to be a reliable and valid tool for detecting depressive symptoms and their changes over time in the general population and psychiatric settings (Weissman et al., 1977). The sensitivity and specificity of the Chinese CES-D in screening for depressive illness in community respondents was reported to be $92 \%$ and $91 \%$, respectively, with a classification rate of $91.8 \%$ at a cut-off point of 15 (Chien \& Cheng, 1985). The internal consistency (Cronbach $\alpha$ coefficient) of the Chinese CES-D were reported to be
0.89 and 0.92 in a community sample of 2,919 adults aged 18 to 40 in Taiwan (personal communication), and a college-based sample of 273 students in China (Zhang \& Norvilitis, 2002), respectively.

\section{Statistical Analysis}

The pre-selected alpha value was 0.05 . For the first 8 SIS items, the overall agreement and the generalized kappa values were calculated for inter-rater reliability among 10 raters on 18 patients. The Cronbach's alpha coefficient was calculated for internal consistency. Spearman rank correlation, intraclass correlations, and paired $t$-test were computed to test the stability of the repeated measures (test-retest reliability) of the last 7 self-reported items in the SIS. Exploratory factor analysis was conducted by taking the polychotomous data scale into consideration. We calculated the matrix of polychoric correlation coefficient on 15 SIS items, and then performed principal component analysis with extraction method, followed by oblimin rotation method which took into consideration the inter-factor correlation. Pearson correlation was computed for the correlations between the subscales and total scores of the SIS, and CES$\mathrm{D}$ scores by gender. The difference in these correlations between male and female subjects was statistically tested. The mean scores of the subscales of the SIS were compared between male and female subjects and among the four age groups ( $\leq 20,21$ to 40,41 to 60 , $\geq 61$ ) using one-way analysis of variance (ANOVA) and nonparametric methods. The Kolmogorov-Smirnov normality tests showed that the distribution of all of the variables violated the normality assumption (all $p<$ 0.001). Therefore, in addition to ANOVA with Bonferron's adjustment for post hoc multiple comparisons, we also used nonparametric methods (Mann-Whitney test and Kruskal-wallis test) to test the mean differences of these variables between male and female subjects and among the four age groups, respectively. Cohen's $d$ was used to compute the effect size (standardized difference between the two means) for the males and fe- 
males (Cohen, 1988). Statistical analyses were performed with SAS, version 9.1 (SAS Institute, Cary, N.C.).

\section{RESULTS}

\section{Inter-Rater Reliability}

For the 8 interview items, their percent agreements were high, ranging from 0.73 to 0.94 and 0.76 to 0.91 in the 10 research team members and the 12 interviewers, respectively. The generalized kappa, which takes the chance agreement into consideration, ranged from 0.38 to 0.83 and 0.42 to 0.69 , respectively, in the two groups (Table 1). The results indicated a comparable and acceptable inter-rater reliability between the two groups.

\section{Test-Retest Reliability}

The 7 self-reported items of the Chinese SIS demonstrated good test-retest reliability with the Spearman rank correlation ranging from 0.72 to 1.00 (Table 1). There were no statistical differences between the first and second measurements of the 7 items ( $\mathrm{p}$ values ranging from 0.163 to 1 in paired $t$ tests), indicating the stability of the repeated measures.

\section{Factor Structure of the Chinese SIS}

Table 2 presents results from factor analysis. There were 3 factors with eigenvalues exceeding unity, accounting for a cumulative total variance of $92.9 \%$. All the items in each of the factors loaded high $(>0.50)$. Factor I, Precautions, contains items 1-4; Factor II, Planning, includes items 5-7; and Factor

TABLE 1

Inter-Rater and Test-Retest Reliability of the Chinese Suicide Intent Scale (SIS)

\begin{tabular}{|c|c|c|c|c|c|c|c|}
\hline \multirow[b]{3}{*}{$\begin{array}{l}\text { SIS } \\
\text { Items }\end{array}$} & \multirow[b]{3}{*}{ Description } & \multicolumn{4}{|c|}{ Inter-rater Reliability $(N=18)$} & \multirow{2}{*}{\multicolumn{2}{|c|}{$\begin{array}{c}\text { Test-retest } \\
\text { Reliability } \\
(N=18)\end{array}$}} \\
\hline & & \multicolumn{2}{|c|}{$\begin{array}{c}\text { Agreement } \\
(\%)\end{array}$} & \multicolumn{2}{|c|}{$\begin{array}{c}\text { Generalized } \\
\text { Kappa }\end{array}$} & & \\
\hline & & $\underset{\mathrm{I}^{\mathrm{a}}}{\text { Group }}$ & $\begin{array}{l}\text { Group } \\
\text { II }^{\mathrm{b}}\end{array}$ & $\begin{array}{l}\text { Group } \\
\mathrm{I}^{\mathrm{a}}\end{array}$ & $\begin{array}{l}\text { Group } \\
\text { II }^{\mathrm{b}}\end{array}$ & $\gamma$ & ICC \\
\hline 1 & Isolation & 91 & 89 & 0.73 & 0.68 & & \\
\hline 2 & Timing & 73 & 79 & 0.38 & 0.47 & & \\
\hline 3 & Precautions Against Discovery & 83 & 86 & 0.62 & 0.63 & & \\
\hline 4 & Act to Gain Help & 87 & 82 & 0.57 & 0.53 & & \\
\hline 5 & Final Acts & 86 & 76 & 0.54 & 0.42 & & \\
\hline 6 & Degree of Planning & 89 & 88 & 0.69 & 0.65 & & \\
\hline 7 & Writing a Note & 94 & 91 & 0.83 & 0.69 & & \\
\hline 8 & Overt Communication of Intent & 83 & 80 & 0.61 & 0.54 & & \\
\hline 9 & Purpose of Attempt & - & - & - & - & 1.00 & 1.00 \\
\hline 10 & Expectation Regarding Fatality & - & - & - & - & 0.86 & 0.88 \\
\hline 11 & Concept of Lethality & - & - & - & - & 0.89 & 0.87 \\
\hline 12 & Seriousness & - & - & - & - & 1.00 & 1.00 \\
\hline 13 & Ambivalence to Living & - & - & - & - & 0.72 & 0.74 \\
\hline 14 & Concept of Reversibility & - & - & - & - & 0.89 & 0.88 \\
\hline 15 & Degree of Premeditation & - & - & - & - & 1.00 & 1.00 \\
\hline
\end{tabular}

Abbreviations: $\gamma=$ Spearman Rank Correlation, ICC $=$ intraclass correlation.

${ }^{a}$ among 10 research team members; ${ }^{b}$ among 12 interviewers conducting the interviews among 592 subjects. 
TABLE 2

Factor Structure of the Chinese SIS Among 592 Community Respondents with Deliberate Self Harm

\begin{tabular}{clccc}
\hline & & \multicolumn{3}{c}{ Factor Loadings } \\
\cline { 3 - 5 } Items & & Precautions & Planning & Seriousness \\
\hline \multirow{2}{*}{1} & Isolation & $\mathbf{0 . 7 7}$ & 0.26 & 0.41 \\
2 & Timing & $\mathbf{0 . 7 5}$ & 0.22 & 0.40 \\
3 & Precautions Against Discovery & $\mathbf{0 . 8 1}$ & 0.34 & 0.45 \\
4 & Act to Gain Help & $\mathbf{0 . 6 7}$ & 0.13 & 0.33 \\
5 & Final Acts & 0.31 & $\mathbf{0 . 8 7}$ & 0.57 \\
6 & Degree of Planning & 0.42 & $\mathbf{0 . 7 3}$ & 0.59 \\
7 & Writing a Note & 0.20 & $\mathbf{0 . 8 7}$ & 0.44 \\
8 & Overt Communication of Intent & 0.10 & 0.40 & $\mathbf{0 . 5 0}$ \\
9 & Purpose of Attempt & 0.45 & 0.43 & $\mathbf{0 . 8 0}$ \\
10 & Expectation Regarding Fatality & 0.42 & 0.53 & $\mathbf{0 . 8 8}$ \\
11 & Concept of Lethality & 0.46 & 0.54 & $\mathbf{0 . 8 4}$ \\
12 & Seriousness & 0.48 & 0.51 & $\mathbf{0 . 9 5}$ \\
13 & Ambivalence to Living & 0.48 & 0.43 & $\mathbf{0 . 8 9}$ \\
14 & Concept of Reversibility & 0.45 & 0.36 & $\mathbf{0 . 7 3}$ \\
15 & Degree of Premeditation & 0.42 & 0.69 & $\mathbf{0 . 7 6}$ \\
Eigenvalue & 1.44 & 1.05 & 7.31 \\
Internal consistency (Cronbach's alpha ) & 0.74 & 0.73 & 0.89 \\
\hline
\end{tabular}

Extraction Method: Principal Component Analysis.

Rotation Method: Oblimin (tau $=0)$.

Cumulative variance $=92.9 \%$

Au: Please explain boldface

III, Seriousness, comprises items 8-15. They can be treated as three subscales of the Chinese SIS.

\section{Internal Consistency}

The Cronbach's alpha coefficients for the total SIS and the three subscales (Precautions, Planning, and Seriousness) among all 592 subjects were $0.88,0.74,0.73$, and 0.89 , respectively (Table 2). The internal consistency of the total and subscales of the Chinese SIS did not differ between male and female patients, between subjects with higher and lower educational levels, or across the four age groups. The Cronbach's alpha coefficients in men and women were 0.88 and 0.87 for the total scale, and were 0.74 and $0.73,0.72$ and 0.73 , and 0.89 and 0.88 for subscales Precautions, Planning, and Seriousness, respectively. The corresponding figures in participants with an education level of junior high school (9 years) or lower and senior high school or higher were 0.88 and 0.87 for the total scale, 0.73 and $0.74,0.72$ and 0.75 , and 0.89 and 0.87 for subscales Precautions, Planning, and Seriousness, respectively. The corresponding figures ranged from 0.85 to $0.89,0.68$ to $0.77,0.70$ to 0.84 , and 0.86 to 0.89 in subjects with ages $\leq 20,21$ to 40,41 to 60 , and $\geq 61$, respectively.

\section{Correlations among SIS and between SIS and CES-D}

The correlations between the total scale and subscales of the Chinese SIS were high, ranging from 0.62 (Planning) to 0.94 (Seriousness), and were moderate among the 3 subscales, ranging from 0.27 to 0.44 . The Seriousness subscale had the relatively high correlation coefficient with the total score, 
explaining about $70 \%$ of the total SIS score variance. The correlations were low to moderate between CES-D and the total (0.35) and subscales of the Chinese SIS (0.19 for Precautions, 0.26 for Planning, and 0.35 for Seriousness).

Table 3 lists the correlation coefficients between the Chinese SIS and CES-D for males (upper right) and females (lower left). The patterns of correlations in males and females were largely similar to that observed in the total sample with three exceptions. Compared to their male counterparts, female respondents demonstrated significantly higher correlations between the CES-D and the total scale and Seriousness subscale of the Chinese SIS and between the Precaution and Planning subscales of the Chinese SIS.

\section{Gender and Age Effect}

Table 4 shows that gender and age have significant effects on the total score of the Chinese SIS and the score of the Seriousness subscale. These two scores were significantly higher in men than in women. There was no gender difference in scores for both Precautions and Planning subscales. Among the four age groups, these two scores were significantly higher in the eldest $(\geq 61)$ than in the other three groups, particularly for scores of the Seriousness subscale (Adjusted $\mathrm{p}<0.05$ by Bonferroni adjustment). The scores of the Precautions and Planning subscales did not differ across the four age groups.

The effect of age and gender on the Chinese SIS scores was further examined using Mann-Whitney and Kruskal-Wallis test. The results were similar to those using the ANOVA (Table 4).

\section{DISCUSSION}

\section{Methodological Consideration}

This is the first study to examine the psychometric properties of the SIS in a nonWestern country. The study includes a large representative sample of community respondents with DSH, and major psychometric properties (inter-rater reliability, test-retest reliability, internal consistency, psycholinguistic equivalence, construct validity, and concurrent validity) have been examined with acceptable results. However, several limitations in this study need to be taken into consideration while interpreting the findings. There is no follow-up information to examine the predictive validity of the Chinese SIS (Chien \& Cheng, 1985; Mieczkowski et al., 1993). Without recruitment of control subjects, we cannot examine the discriminant validity of the instrument between subjects

TABLE 3

Correlations Between the Chinese SIS and CES-D for Males (Upper Right) and Females (Lower Left) Among 592 Community Respondents with Deliberate Self Harm

\begin{tabular}{lccccc}
\hline $\begin{array}{l}\text { Male }(n=209) \\
\text { versus Female }(n=383)\end{array}$ & $\begin{array}{c}\text { SIS } \\
\text { Total }\end{array}$ & $\begin{array}{c}\text { Precautions } \\
\gamma(p \text { value })\end{array}$ & $\begin{array}{c}\text { Planning } \\
\gamma(p \text { value })\end{array}$ & $\begin{array}{c}\text { Seriousness } \\
\gamma(p \text { value })\end{array}$ & $\begin{array}{c}\text { CES-D } \\
\gamma\left(p \text { value }^{*}\right)\end{array}$ \\
\hline SIS Total & - & $0.66(0.071)$ & $0.59(0.096)$ & $0.94(0.353)$ & $0.29(0.006)$ \\
Precautions & 0.70 & - & $0.17(0.001)$ & $0.42(0.239)$ & $0.18(0.319)$ \\
Planning & 0.64 & 0.31 & - & $0.52(0.389)$ & $0.22(0.123)$ \\
Seriousness & 0.93 & 0.45 & 0.53 & - & $0.29(0.005)$ \\
CES-D & 0.40 & 0.20 & 0.28 & 0.40 & - \\
\hline
\end{tabular}

$p$ value of 2-tailed zero correlation tests were all less than 0.001 .

Abbreviations: $\gamma=$ Spearman rank correlation coefficients, SIS = Suicide Intent Scale, CES-D = Center for Epidemiologic Studies-Depression Scale

${ }^{*} p$ value of differences of correlation coefficient test between male and female subjects in parenthesis. 


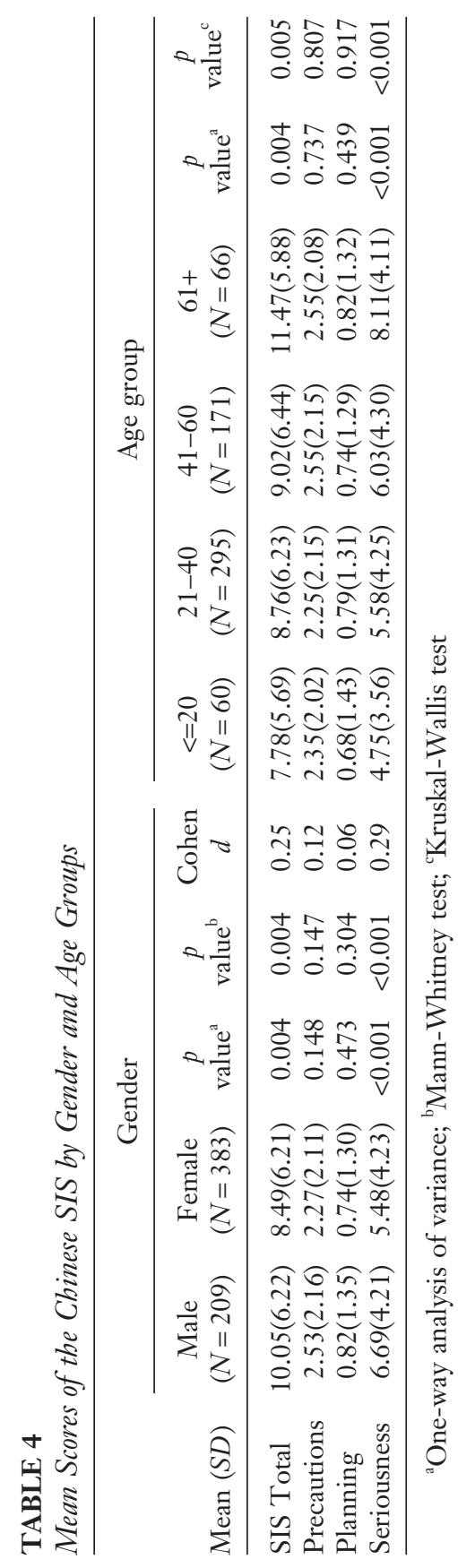


with DSH and normal controls. The concurrent validity was only conducted with a screening tool for depression (CES-D), and the correlation between Chinese SIS and lethality of suicide methods used by respondents was not examined.

Finally, without information about the psychiatric diagnosis of respondents, we were not able to examine the association between diagnostic categories and the extent of suicide intent. These limitations will be tackled in our further studies of the Chinese SIS.

\section{Reliability}

Our findings showed that the ratings of the Chinese SIS were rather stable over time for the self-report items and were not influenced by individual raters for the interviewer-judged items with one exception: selection of the timing for suicidal acts. The relatively lower agreement in "timing" implies that there is a need to improve the judgment regarding whether subjects making DSH thought that their acts could be found or not. In contrast, "writing a note" had the highest kappa coefficient as there was objective evidence about the presence/absence of wills or last words. The high internal consistency of the Chinese SIS was observed in both female and male respondents and across different age groups, regardless of educational levels. The high stability of the Chinese SIS indicates that changes in its score in clinical studies can be well interpreted as due to intervention effects, rather than due to random temporal fluctuations in scale scores.

\section{Construct Validity}

Previous studies of the factor structure of SIS in western populations identified two to four factors (Diaz et al., 2003). Similar to a study with the English SIS (Silver et al., 1971), this study found a three-factor solution with the Chinese SIS. Comparing these two studies, exactly the same items 1-4 loaded high in the factor Precautions in the Chinese SIS and the factor Isolation Behav- iors in the English SIS (Spirito et al., 1996). Item 15 (degree of premeditation) included in the factor Planning Activities of the English SIS (items 5, 6, \& 15) loaded highest in the factor Seriousness of the Chinese SIS. Item 7 (writing a note) and item 8 (overt communication of intent) excluded in the English SIS (Spirito et al., 1996) were assigned to the factors Planning and Seriousness of the Chinese SIS, respectively. We also found similar mean total scores of the Chinese and English SIS versions (Spirito et al., 1996) among subjects with DSH.

\section{Concurrent Validity}

The moderate correlations of SIS scores with measures of depression (Chance et al., 1994; Minkoff et al., 1973; O'Brien et al., 1987; Platt \& Dyer, 1987; Silver et al., 1971) and hopelessness (Beck \& Herman, 1974; Platt \& Dyer, 1987) in previous reports was replicated in this study. We have further found a moderate correlation between the CES-D and two factors of the Chinese SIS (Seriousness and Planning) and a low correlation between CES-D and one Chinese SIS factor (Precaution). The low correlation with "Precaution" might indicate that isolation behavior and prevention of discovery may be less related to the severity of depressive symptoms.

\section{Gender and Age Effect}

Our finding of a significantly stronger suicidal intention in male subjects with DSH, particularly in the seriousness dimension, than their female counterparts is consistent with most previous studies (Diaz et al., 2003; Hawton, 2000). However, no gender difference in suicidal intention was reported in an international study in Europe among suicide attempters (Hjelmeland et al., 2002). Conversely, our female respondents had a significantly higher correlation than their male counterparts between the CES-D and the Chinese SIS. This may suggest that the intensity of suicide intention is more related to depressive symptoms in women (Hesketh, 
Ding, \& Jenkins, 2002), and early detection and management of depression might be more important for suicide prevention in the female population. For males, in addition to depression, it might be crucial to identify other symptoms correlated with their suicide intention for suicide prevention. Our finding of a higher score of seriousness in suicide intent among subjects older than 60 with DSH indicates that more attention should be paid to them, as a stronger suicide intent ascribe an increased risk for suicide in this group (Suominen et al., 2004).

\section{REFERENCES}

Astruc, B., Torres, S., Jollant, F., JeanBaptiste, S., Castelnau, D., Malafosse, A., \& Courtet, P. A. (2004). History of major depressive disorder influences intent to die in violent suicide attempters. 7 Clin Psychiatry, 65, 690-695. Beck, A. T., Beck, R., \& Kovacs, M. (1975). Classification of suicidal behaviors: I. Quantifying intent and medical lethality. $\operatorname{Am} \mathcal{7}$ Psychiatry, 132, 285-287.

Beck, A. T., \& Lester, D. (1976). Components of suicidal intent in completed and attempted suicides. 7 Psychol, 92, 35-38.

Beck, A. T. Schuyler, D., \& Herman, I. (1974). Development of suicidal intent scales. In A.T. Beck \& D.J. Lettieri (Eds.). The Prediction of Suicide. Bowie, MD: Charles Press.

Bertolote, J. M., \& Leischman, F. A. (2002). A global perspective in the epidemiology of suicide. Suicidologi, 7, 6-7.

Chance, S. E., Kaslow, N. J., \& Baldwin, K. (1994). Anxiety and other predictors of severity of suicidal intent in urban psychiatric inpatients. Hosp Community Psychiatry, 45, 716-718.

Cheng, A.T.A. (1995). Mental illness and suicide. A case-control study in east Taiwan. Arch Gen Psychiatry, 52, 594-603.

Cheng, A.T.A., Chen, T. H., Chen, C. C., \& Jenkins, R. (2000). Psychosocial and psychiatric risk factors of suicide: A case-control psychological autopsy study. Br 7 Psychiatry, 177, 360-365.

Cheng, A.T.A., Mann, A. H., \& Chan, A. (1997). Personality disorder and suicide: a casecontrol study. Br 7 Psychiatry, 170, 441-446.

Cheng, A.T.A., \& Lee, C. S. (2000). Suicide in Asia and the Far East. In K. Hawton ed. The international handbook of suicide and attempted suicide. (pp. 29-48). Chichester, England: Fohn Wiley \& Sons.

Chien, C. P., \& Cheng, T. A. (1985). De-

\section{Implications}

Results from this study have suggested that the Chinese SIS is a reliable and valid instrument for assessing suicide intention in the Chinese populations. They might also suggest that the core phenomenon of suicide intent is likely to be culture-general across East and West. The Chinese SIS can be used in clinical settings and in community surveys to assess the extent of suicide intent for its contribution to the risk of suicide and for suicide prevention.

pression in Taiwan: Epidemiological survey utilizing CES-D. Seishin Shinkeigaku Zasshi-Psychiatria et Neurologia Faponica, 87, 335-338.

CoHen J. (1988). Statistical power analysis for the behavioral sciences (2nd ed.). Hillsdale, NJ: Lawrence Earlbaum Associates.

Diaz, F. J., Baca-Garcia, E., Diaz-Sastre, C., Garcia Resa, E., Blasco, H., Braquehais Conesa, D., Et al. (2003). Dimensions of suicidal behavior according to patient reports. Eur Arch Psychiatry Clin Neurosci, 253, 197-202.

Department of Health, Executive Yuan, Taiwan. (2006). Retrieved October 14, 2006, from http://www.doh.gov.tw/statistic/index.htm.

Harriss, L., \& Hawton, K. (2005). Suicidal intent in deliberate self-harm and the risk of suicide: The predictive power of the suicide intent scale. 7 Affect Disord, 86, 225-233.

Haw, C., Hawton, K., Houston, K., \& Townsend, E. (2003). Correlates of relative lethality and suicidal intent among deliberate selfharm patients. Suicide Life Threat Behav, 33, 353364.

Hawton, K. (2000). Sex and suicide. Gender differences in suicidal behaviour. Br $\mathcal{F}$ Psychiatry, 177, 484-485.

Hesketh, T., Ding, Q. J., \& Jenkins, R. (2002). Suicide ideation in Chinese adolescents. Soc Psychiatry Psychiatr Epidemiol, 37, 230-235.

Hjelmeland, H., Hawton, K., Nordvik, H., Bille-Brahe, U., De Leo, D., Fekete, S., et AL. (2002). Why people engage in parasuicide: A cross-cultural study of intentions. Suicide Life Threat Behav, 32, 380-393.

Hjelmeland, H., Stiles, T., Bille-Brahe, U., Ostamo, A., Renberg, E. S., \& Wasserman, D. (1998). Parasuicide. The value of suicidal intent and various motives as predictors of future suicidal behavior. Arch Suicide Res, 4, 209-225. 
Kingsbury, S. J. (1993). Clinical components of suicidal intent in adolescent overdose. 7 Am Acad Child Adolesc Psychiatry, 32, 518-520.

Lönnqvist, J., \& Tolppanen, E.-M. (1985). Outcome of attempted suicide. In P. Pichot, P. Berner, R. Wolf, and K. Thau (Eds.). Psychiatry - the state of the art (pp. 889-894). New York: Plenum Press.

Mieczkowski, T. A., Sweeney, J. A., HaAs, G. L., Junker, B. W., Brown, R. P., \& Mann, J. J. (1993). Factor composition of the Suicide Intent Scale. Suicide Life Threat Behav, 23, 37-45.

Minkoff, K., Bergman, E., Beck, A. T., \& Beck, R. (1973). Hopelessness, depression, and attempted suicide. Am 7 Psychiatry, 130, 455-459.

NHS Centre for Reviews and Dissemination. (1998). Effective Health Care Bulletin: Deliberate self-harm. Effective Health Care, 4, $1-12$.

O’Brien, G., Holton, A. R., Hurren, K., Watt, L., \& Hassanyeh, F. (1987). Deliberate self harm-correlates of suicidal intent and severity of depression. Acta Psychiatr Scand, 75, 474477.

O’Donnell, I., Farmer, R., \& Catalan, J. (1996). Explaining suicide: The views of survivors of serious suicide attempts. $B r f$ Psychiatry, 168, 780-786.

Pallis, D. J., Gibbons, J. S., \& Pierce, D. W. (1984). Estimating suicide risk among attempted suicides. II. Efficiency of predictive scales after the attempt. Br 7 Psychiatry, 144, 139-148.

Pierce, D. W. (1981). The predictive validation of a suicide intent scale: A five year followup. Br 7 Psychiatry, 139, 391-396.

Platt, S. D., \& Dyer, J. A. (1987). Psychological correlates of unemployment among male parasuicides in Edinburgh. Br 7 Psychiatry, $151,27-32$.

Phillips, M. R., Yang, G., Zhang, Y., WANG, L., Ji, H., \& Zhou, M. (2002). Risk factors for suicide in China: A national case-control psychological autopsy study. Lancet, 360, 1728-1736.

Samuelsson, M., Jokinen, J., Nordstrom, A. L., \& Nordstrom, P. (2006). CSF 5-HIAA, suicide intent and hopelessness in the prediction of early suicide in male high-risk suicide attempters. Acta Psychiatr Scand, 113, 44-47.

Silver, M. A., Bohnert, M., Beck, A. T., \& Marcus, D. (1971). Relation of depression of attempted suicide and seriousness of intent. Arch Gen Psychiatry, 25, 573-576.

Spirito, A., Sterling, C. M., Donaldson, D. L., \& Arrigan, M. E. (1996). Factor analysis of the suicide intent scale with adolescent suicide attempters. 7 Pers Assess, 67, 90-101.

Suokas, J., \& Lonnqvist, J. (1991). Outcome of attempted suicide and psychiatric consultation: Risk factors and suicide mortality during a five-year follow-up. Acta Psychiatr Scand, 84, 545549.

Suominen, K., Isometsa, E., Heila, H., Lonnovist, J., \& Henriksson, M. (2002). General hospital suicides - a psychological autopsy study in Finland. Gen Hosp Psychiatry, 24, 412416.

Suominen, K., Isometsa, E., Ostamo, A., \& Lonnqvist, J. (2004). Level of suicidal intent predicts overall mortality and suicide after attempted suicide: A 12-year follow-up study. BMC Psychiatry, 4, 11.

Wang, L. J., Phillips, M., Huang, Z. J., Zhang, Y. P., ZhaO, Y. X., \& YANG, G. H. (2003). [Evaluation on the accuracy of reported suicides in the Chinese population]. Zhonghua Liu Xing Bing Xue Za Zhi, 24, 889-892.

Weissman, M. M., Sholomskas, D., Pottenger, M., Prusoff, B. A., \& Locke, B. Z. (1977). Assessing depressive symptoms in five psychiatric populations: A validation study. Am $\mathcal{F}$ Epidemiol, 106, 203-214.

Wetzel, R. D. (1976). Factor structure of Beck's Suicide Intent Scale. Psychol Rep, 40, 295302.

Yip, P. S., Law, C. K., \& Law, Y. W. (2003). Suicide in Hong Kong: Epidemiological profile and burden analysis, 1981 to 2001. Hong Kong Med 7, 9, 419-426.

Zhang, J., \& Norvilitis, J. M. (2002). Measuring Chinese psychological well-being with Western developed instruments. 7 Pers Assess, 79, $492-511$. 